\title{
DATA STRUCTURES FOR ROAD CONDITION AVI FiLE Video AUgMENTATION
}

\author{
MiHIC, S. \& IVETIC, D.
}

Abstract: The paper presents data structures for ROad Measurement and Data Acquisition System's (ROMDAS) road condition video augmentation. The ROMDAS system collects and analyses the road-condition state through video and the nonperceptible discrete data acquired by measurement devices. Due to the separate storage of videos and the corresponding data, engineers have to search the videos manually in order to find details of interest provided by data analysis. We propose the integration and encapsulation of the discrete data into the video file. We have designed and implemented Augmented Video stream Framework (AVF) that enables creation, search and playback of such augmented AVI files for effective road surveying. The AVF uses a type system similar to $C++$ and Java programming languages and offers encapsulation of arbitrary data.

Key words: data structures, information retrieval, video augmentation, road surveying
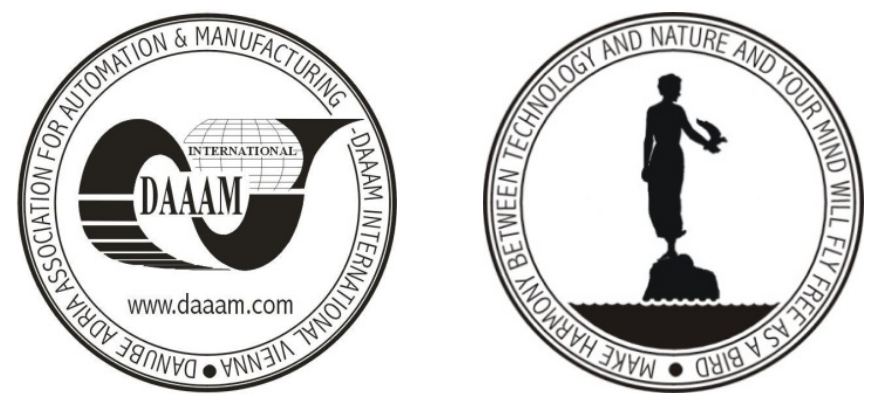

Authors' data: Teaching and research assistant ( $\mathrm{PhD}$ student). Mihic, S[rdan]; Associate professor PhD of CS. Ivetic, D[ragan], University of Novi Sad, Faculty of Technical Sciences, Department for Computing and Automatics, Trg Dositeja Obradovica 6, 21000, Novi Sad, Republic of Serbia, smihic@uns.ac.rs, ivetic@uns.ac.rs

This Publication has to be referred as: Mihic, S[rdan] \& Ivetic, D[ragan] (2009). Data Structures for Road Condition AVI File Video Augmentation, Chapter 13 in DAAAM International Scientific Book 2009, pp. 117-126, B. Katalinic (Ed.), Published by DAAAM International, ISBN 978-3-901509-69-8, ISSN 1726-9687, Vienna, Austria

DOI: $10.2507 /$ daaam.scibook.2009.13 